\title{
Speaking out of turn? Taking the initiative in teacher-fronted classroom interaction
}

\author{
Abstract \\ Teacher-fronted interaction is generally seen to place limitations on the \\ contributions that learners can make to classroom discourse and the conclusion is \\ that learners are unable to experiment with, for example, turn-taking mechanisms. \\ This article looks at teacher-fronted interaction in the language classroom from \\ the perspective of learner talk by examining how learners might take the initiative \\ during this apparently more rigid form of interaction. Detailed microanalysis of \\ classroom episodes, using a conversation analysis institutional discourse \\ approach, shows how learners orient to the institutional context to make \\ sophisticated and make effective use of turn-taking mechanisms to take the \\ initiative and direct the interaction, even in the controlled environment of teacher- \\ fronted talk. The article describes some of the functions of such learner initiative, \\ examines how learners and teachers co-construct interaction and how learners can \\ create learning opportunities for themselves. It also briefly looks at teacher \\ reactions to such initiative. The article concludes that learner initiative in teacher- \\ fronted interaction may constitute a significant opportunity for learning and that \\ teachers should find ways of encouraging such interaction patterns.
}

\section{Introduction}

The language classroom, like other classrooms, represents a particular institutional context in which participants come together to achieve the specific goal of 
teaching and learning. Classroom discourse is therefore a form of institutional talk and as such has certain characteristics, described, for example, by Walsh (2006, p.5). This is evident in particular in the turn-taking system which, in teacherfronted interaction, is generally highly constrained and reflects the asymmetrical role relationship between teachers and learners. In most classrooms, it is the teacher who decides who can talk, when and about what (Greenleaf \& Freedman, 1993; Walsh, 2006). Van Lier (1996, pp.184-185) points out that, while this may have advantages of control and efficiency, the consequences are that:

... this efficiency comes at the cost of reduced student participation, less expressive language use, a loss of contingency, and severe limitations on the students' employment of initiative and self-determination. Yet such a view of language classroom interaction may be reductive. Allwright (1984, p.159), for example, points out that interaction is a 'coproduction' and that teachers and learners are jointly responsible for managing classroom interaction while Johnson (1995, p.39) states that:

... students actively engage, to a greater or lesser degree, in the creation of what occurs in classrooms and, thus, affect classroom events as much as they are affected by them.

In spite of the recognition of the importance of learner participation, involvement and initiative in the language classroom (van Lier 1988, p.90), there has been little attempt to either to investigate what is meant by learner initiative or to analyse the ways in which this initiative is expressed and the effects it may have on classroom interaction. 
This article represents an initial attempt to describe learner initiative during English language lessons and in one particular form of classroom organisation, that of teacher-fronted interaction. By taking a conversation analysis (CA) institutional discourse approach (Seedhouse, 2004), this article shifts the perspective from teachers to learners in order to show how the latter are able to make effective use of turn-taking mechanisms to take the initiative and direct the talk, even in the more controlled environment of teacher-fronted interaction. What learners so with their initiative is described, and the ways in which learners can create learning opportunities for themselves (Kumaravadivelu, 2001) are examined.

\section{Classroom Talk}

Much previous research into classroom talk focused on teacher-fronted interaction has been based on Sinclair and Coulthard's (1975) highly influential discourse analytical approach and in particular on their three part exchange of teacher Initiation, learner Response and teacher Feedback or Evaluation (IRF/E), which is seen as typical of classroom interaction.

There have been a number of studies of language classroom discourse that have criticised the use of the IRF exchange because of the lack of opportunities afforded for language learning and particularly for developing communicative competence. Kaspar (2001, p.518), for example, points out that research on classroom-based learning of pragmatics and discourse generally views the IRF pattern as 'an unproductive interactional format' in that teachers control topic management and therefore students are 'not provided opportunities for developing 
the complex interactional, linguistic and cognitive knowledge required in ordinary conversation' (ibid). Moreover, studies such as that by Nunan (1987) conclude that the use of IRF exchanges placed severe limitations on the contributions that learners can make to the interaction in that possibilities to engage in 'genuine communication' are scarce.

More recently, however, teacher-fronted interaction has been rehabilitated to a certain extent. In particular, it has been acknowledged that critics who focus on the lack of 'genuine communication' in classroom talk tend to equate such talk with 'conversation', which, as Seedhouse (1996, p.17) points out, has a precise sociolinguistic meaning, and is, by definition, a non-institutional form of discourse. It is therefore difficult, if not impossible, to reproduce conversation in the institutional setting of a classroom. Seedhouse (ibid. p.18) goes on to note that To replicate conversation, the lesson would therefore have to cease to be a lesson in any understood sense of the term and become a conversation which did not have any underlying pedagogic purpose, which was not about English or even, in many situations, in English.

The classroom, therefore, is a social context in its own right (Johnson, 1995;

Walsh, 2002), with its own goals and rules of communication (Seedhouse, 2004). Cullen (1998, p.180) concludes that communicative talk in classrooms needs to be defined in terms of what is communicative in a classroom context, while Walsh (2002, p.4) notes that, in order to understand classroom discourse, the relationship between language use and pedagogic goals needs to be recognised.

Recent research has shifted more towards focusing in particular on looking at how teacher talk can best support learning, through, for example, the use of the 
F-move (Cullen, 1998, 2002; Jarvis \& Robinson, 1997; Kasper, 2001; Nassaji \& Wells, 2000; Walsh, 2002).

Cullen (1998) points out that many features of teacher talk that are traditionally considered 'uncommunicative' can in fact be entirely appropriate in the context of the pedagogical goals of the classroom and support for learning. Cullen (2002) compared what he called evaluative and discoursal F-moves. The former focus on the form of the learners' responses while the latter concern the content. It is the latter in particular through which the teacher may provide 'a rich source of message-oriented target language input as $\mathrm{s} / \mathrm{he}$ reformulates and elaborates on student contributions, and derives further initiating moves from them' (ibid, p.122). Jarvis and Robinson (1997, p. 214) also point to how the teacher's F-move can be used to support learning through formulation and alignment of meaning, which they link to the Vygotskian idea of supporting learners' Zone of Proximal Development (ZPD).

While teacher-fronted interaction has therefore been rehabilitated in more recent research, all the studies cited above focus on teacher talk and how teachers can create opportunities for learning. Much less research to date has focused on teacher-fronted interaction and its potential for learning from the point of view of learner talk.

Although turns in which learners take the initiative during the more constrained turn-taking typical of teacher-fronted interaction are clearly not as frequent as turns allocated by the teacher, the data from the current study show that they do exist and are the demonstration that this strategic option is in fact available to learners. Moreover, by taking the initiative, learners can direct the 
interaction in such a way that it responds more closely to their needs, and at the same time develops their skills in managing interaction (Allwright, 1984; van Lier, 1988).

\section{Approaches to analysis}

Most the studies cited above still focus on the IRF pattern as the basic unit of analysis, yet this discourse analytical approach has been criticised (see, for example, Drew \& Heritage, 1992, pp.10-16; Levinson, 1983, pp. 286-294). A fundamental weakness in such an approach lies in the imposition of categories defined a priori onto the data being studied. Moreover, these categories are static and cannot capture the variety of functions of language, the variability of interpretation and the wealth of interaction that goes on in the classroom, a point illustrated very clearly by Seedhouse (2004, pp. 58-66), for example. Seedhouse (ibid.) compares two extracts from language classrooms which both ostensibly follow an IRF sequence. Through a CA institutional-discourse analysis, he demonstrates how one of the sequences is far more complex and dynamic than the other. As Seedhouse (ibid., p.63) affirms, 'the IRF/IRE cycles perform different interactional and pedagogical work according to the context in which they are operating'. Therefore, a key advantage to the CA instituional-discourse approach is that it is able to uncover interactional complexities that DA approaches cannot.

The basic tenet of a CA instituional-discourse approach is that institutional discourse is oriented to achieving specific goals. As Seedhouse (2004, p.96) explains:

CA instiutional-discourse methodology attempts to relate not only the 
overall organization of the interaction, but also individual interactional devices to the core institutional goal. CA attempts, then, to understand the organization of the interaction as being rationally derived from the core institutional goal.

Such an approach analyses sequences of talk, rather than single utterances, examining language 'in its interactional environment' (Richards and Seedhouse 2005 , p. xv), but at the same time, it identifies the way that individual turns are constructed and how participants orient to each other and to the context. It is therefore better able to uncover the variety of pedagogical purposes and lingustic practices used in the classroom (Walsh, 2006 p.53) and, through detailed analysis of the partcipants' interactional behaviour, reveal which particular aspects of the insitutional setting are being oriented to (Mori, 2002, p.326).

However, DA approaches are not incompatible with CA, and in particular can be useful in identifying the speech moves in interaction (Seedhouse 2004, p.66). What is needed is

.. a much broader perspective which concentrates on the relationship between pedagogical focus and the organization of the interaction, in particluar the organization of turns, sequence, repair and topic. (ibid)

The study reported here therefore integrates an initial discourse analytical approach based on the analysis of classroom extracts using the basic IRF pattern in order to identify relevant sequences, with microanalysis using the tools of CA insitutional-discourse. This microanalysis focuses on the key areas of institutional discourse organisation identified by Heritage (2004): turn-taking organisation, turn design, sequence organisation, lexical choice and asymmetry of roles in order 
to allow for an 'emically-oriented (i.e. partcipant-relevant) perspective (Markee and Kaspar 2004, p. 491). Such an approach allows for a more nuanced and detailed analysis of how learners orient to pedagogical goals in taking the initiative.

\section{Methodology and data}

The data for this study were obtained from non-participant observations and audio-recordings of regularly scheduled adult EFL (English as a Foreign Language) evening classes held at a university language centre in Italy. The learners were mostly university students, together with some members of university staff and local townspeople, and the lessons were at pre-intermediate, intermediate and upper-intermediate level. The groups were relatively small, with between 15 and 18 learners in each.

The classes were held by five different teachers. They were all qualified and experienced EFL teachers except Teacher D (who was in her first year of teaching and not qualified at the time), they were all female except Teacher $\mathrm{C}$ and they were all British except Teacher E (who was from the US). The final database consisted of three upper-intermediate lessons by Teacher A, three intermediate lessons by Teacher B, two intermediate lessons by Teacher C, one preintermediate lesson by teacher $\mathrm{D}$ and two pre-intermediate lessons by Teacher $\mathrm{E}$ This represents a total of 11 lessons and approximately 12 hours of recording.

In order to identify episodes of learner initiative in the recordings and analyze the role such initiative has in classroom interaction, the first step was to develop a definition of initiative by applying those previously identified in the 
literature to the audio-recordings. At the same time, the definition was refined on the basis of the evidence from the recordings themselves. Thus initially, definition and analysis went hand in hand.

In one of the few previous attempts to actually define learner initiative, Mehan and Griffin (1980, p. 378) maintain that, in order to be considered an initiative, a learner contribution must occur at an appropriate moment in the lesson, which they define as at the completion of an IRF sequence, and there must be uptake by the other participants in the lesson. Mehan and Griffin (ibid.) do not explain why only the completion of an IRF sequence is considered an appropriate moment for learner initiatives and data from the current study showed that learner initiative can occur at any point in an IRF sequence, not only upon completion. However, it seems clear that, in order to affect interaction patterns and count as initiative, a learner's turn must gain the 'main floor' and not just be limited to a 'sub-floor' (van Lier, 1988, p. 103). Van Lier (ibid.) explains that a turn gains the main floor when two or more people are involved in the interaction and 'the attention of all those present is sought and obtained'. This is opposed to the subfloor, where a turn is aimed at or intended for only part of the audience. Gaining the main floor means that there will be uptake, normally by the teacher, but possibly by other learners too. In his discussion of learner initiative, van Lier also states that the student's turn must be self-selected. Using these two criteria it is possible to develop a working definition based on two main conditions:

a. The learner's turn is self-selected but not in response to a teacher allocation of turn.

b. the learner's turn gains the 'main floor' and is not just limited to a 'sub floor'. 
The following is a clear example of learner initiative (see appendix for transcription conventions used):

\section{TB 2.7}

$01 \mathrm{~T} \quad \uparrow a l l o r a$, (now then) what about (the) bi::ke, my favourite form $02 \quad$ of transporta[tion ]

$03 \rightarrow \mathrm{F} \quad$ [(there)] there another dis disadvant[age]

$04 \mathrm{~T}$ [an ]other 05 disadvantage about [trains, ]

$06 \rightarrow \mathrm{F} \quad$ [strikes]

$07 \mathrm{~T} \quad$ (.) oh yeah that can be very (.) uncomfortable.

In this extract, the class is discussing the advantages and disadvantages of different types of transport. In line 1, the teacher is moving on to a new form of transport, the bike, but the female learner takes the initiative to re-open the discussion of the disadvantages of train travel.

\subsection{Data analysis}

Once a satisfactory definition had been elaborated, all the episodes of learner initiative were identified in the audio-recordings and a total of 206 turns involving learner initiative were initially found in the data. All examples of learner initiative were then roughly transcribed. In deciding how much context was sufficient for the purposes of transcribing extracts, Sinclair and Coulthard's (1975) idea of boundary moves was used.

As noted in section 3 above, the use of a priori categories is not entirely incompatible with a CA approach to analysis. Nevertheless, while CA is increasingly being proposed as a methodological resource for Second Language Acquisition (SLA) research (He, 2004; Markee, 2008; Markee \& Kasper, 2004), there is some reluctance in such research to work with 'traditional' SLA categories, generally associated with etic approaches to interaction, as opposed to 
the emic perspective of CA (Markee and Kasper 2004, p. 494). However, the key issue is not what labels are given to interactional features, but how the analysis is carried out. SLA categories can provide a useful basis for an initial overview of patterns in the data as a preliminary step towards a more detailed CA analysis which focuses in participants' construction of, and orientation to, ongoing activities and this is the approach taken to analysis in the current study.

Preliminary examination of each example of initiative was made to identify what learners actually do with their initiative in the classroom talk at the most general level. This initial process showed that learner initiative focuses on four broad areas, or orientations, the first three of which correspond to the classroom contexts identified by Seedhouse (2004):

a. Orientation to the activity at hand in Procedural Contexts (ibid.). This is when the learner focuses on the current classroom activity. Initiative in this case is directed towards reaching an understanding of the activity and typically concerns reactions to instructions from the teacher or in the textbook.

b. Orientation to language in Form and Accuracy Contexts (ibid.). This refers to initiative in which learners are concerned with the language as the object of study and their understanding of the language system.

c. Orientation to talk in Meaning and Fluency Contexts. This refers to those occasions when learners take the initiative to intervene in classroom discussion and depends on the type of talk taking place.

d. Conversational routines. This area concerns learners initiating the first part of a conversational routine (Coulmas, 1981), typically greetings or leave-takings.

All examples of initiative were then further analyzed in order to identify 
possible patterns within each area. It soon became apparent that initiatives oriented to activity and language focused predominantly on what SLA researchers have labelled comprehension checks, clarification requests, information requests and hypothesis testing (Allwright \& Bailey, 1991; Long, 1983; Pica, 1987), which are considered by SLA researchers to be key in promoting language learning (Long, 1983; Pica 1987).

Therefore, detailed microanalysis focused on learner initiative oriented to activity and to language. Examples of each type of utterance were subsequently retranscribed in greater detail using CA transcription conventions based on those used in Richards and Seedhouse (2005) (see appendix for transcription conventions used). As Liddicoat (2007, p.12) maintains, different transcriptions allow for the investigation of different aspects of the talk and retranscription is frequent in $\mathrm{CA}$ as researchers refine their insights as a result of the on-going analysis.

Following the methodological position outlined above, in presenting the analysis, the labels from SLA are maintained as a convenient organising principle, while the analysis takes a CA institutional-discourse approach in order investigate how the participants in the interaction are oriented to the pedagogical goals of teaching and learning and the complex interactional work that learners were carrying out with their initiatives.

\section{Analysing learner initiative}

\subsection{Confirmation checks}

In the database used in this study, the most common use of learner initiative was 
that of confirmation checks oriented to activity or to language. Allwright and Bailey (1991, p. 123) define confirmation checks as "the speaker's query as to whether or not the speaker's (expressed) understanding of the interlocutor's meaning is correct". The following is an example of a confirmation check oriented to activity:

\section{TC 1.4}

The teacher is setting up a group decision-making activity

$01 \mathrm{~T} \quad$ you have one hundred units (.) now you must use one hundred,

02 (.) because if you use (.) only ninety, (.) or eighty, (.) then (.)

03 people will not be happy, (.) they will say you have not used

$04 \quad$ (.) your resources, (.) in a correct way.

$05 \rightarrow \quad$ M1 $\quad$ so we must use (.) e::r,

$06 \mathrm{~T}$ every[thing]

$07 \rightarrow$ M1 [all ] every[thing]

$08 \mathrm{~T}$ [yep ]

In this example, the teacher is setting up the activity to be carried out by the learners, what Seedhouse (2004) calls Procedural Context. In line 05, M1 takes the initiative to confirm he has understood the teacher's instructions correctly. In CA terms, the teacher's instructions therefore represent a trouble-source and learner's confirmation check is the start of a repair sequence. The teacher completes the learner's utterance in line 06 , but the teacher's everything could also constitute an answer to the question and the sequence could end here. It is the learner who continues the sequence with his utterance in line 07 , which not only completes his previous turn but also aligns to the teacher's turn with the selfcorrection of all to everything. The teacher shows acceptance of the student's all, hence the overlapping talk in line 08 , by responding to the initial question (yep). This short sequence shows how the participants are both oriented to the procedural context and how they co-construct understanding of the activity at 
hand. What this sequence also shows is how learners may identify trouble-sources in teacher talk, and initiate quite complex repair sequences. Although Seedhouse (2004) dedicates a whole chapter to repair and discusses it in terms of three of his four pedagogical contexts, he does not mention repair in connection with Procedural Contexts, nor does he acknowledge learner-initiated repair, except in connection with learner-learner talk. Yet such instances of learner-initiated repair could be significant from an SLA point of view. Not only does the learner's confirmation check enable him to achieve understanding of the activity at hand but he also obtains information about language use (all vs. everything) and shows uptake.

\subsection{Clarification requests}

The second most common function of learner initiative was in making clarification requests. A clarification request is "a request for further information or help in understanding something the interlocutor has previously said." (Pica, Young, \& Doughty, 1987, p. 124) and again this could be oriented either to activity or to language. The following is an example of a clarification request oriented to language.

\section{TB 2.3}

$01 \mathrm{~T} \quad \uparrow$ you have to travel (.) when the:::, (.) $\mathrm{H},($.$) when the::, (.)$

$02 \quad$ Fabrizia?

03 Fabrizia timetable (.) says you (can)=

$04 \mathrm{~T} \quad=$ that's right (.) good when the timetable (.) says (.) you (.) can.

$05 \quad((4))$

$06 \mathrm{~T} \quad$ and then moving [down

$07 \rightarrow$ Maria [please sorry

08 T yes sorry [yes

09 Maria [what's the meaning of (.) timetable?

$10 \mathrm{~T}$ timetable? (.) the timetable that has (.) all the times: (.) of the 
$\begin{array}{lll} & \text { buses, }= \\ 12 & \text { Maria } & =\end{array}$

In this extract, the interaction in lines 01-04 follows an IRF sequence which contains the trouble-source in line 03. The first opportunity Maria has for repair initiation is following this turn, but she does not take this opportunity, possibly because it would interrupt the IRF sequence. The teacher's $\mathrm{F}$ slot is followed by a long pause in line 5 after the teacher's turn. According to the turntaking rules of the classroom, the next turn should be a teacher Initiation and the learners seem to be oriented to this as none of them self-selects as speaker. In line 06 the teacher starts her next Initiation but is interrupted by Maria's bid for the floor. The placing of the repair initiation allows the opportunity for the teacher to repair the trouble source and does not actually interrupt the new point. However, it does interrupt the teacher and Maria demonstrates her recognition that this does not conform to the relevant institutional norms through the considerable interactional work she carries out, prefacing her repair initiation with a request, followed by an apology. She then waits for the teacher to grant access to the floor (in line 08) before identifying the trouble source and hence inviting repair. Maria has now effectively taken control of the interaction as a teacher response is now the relevant next action. The teacher responds and Maria completes the third part of the three part sequence with her comment in line 12. This extract is interesting for two reasons. Firstly, it shows how learners are able to do complex interactional work in order to successfully gain the floor, work which is necessary in this case as Maria has broken the rules of turn-taking in the classroom by interrupting the teacher's Initiation. Second, Maria gains control over the interaction by 
effectively reversing the speaker order in the three-part exchange, from the usual Teacher-Learner-Teacher to Learner-Teacher-Learner, making the teacher accountable for the answering the question and positioning herself as the speaker in the third slot, which in SLA terms confirms uptake. In this exchange, Maria shows that her orientation to the rules of the speech exchange system is very sophisticated.

\subsection{Information requests}

Two further functions of initiative both occurred in orientation to language and these are information requests and hypothesis testing.

An information request is concerned with obtaining information about the language which goes beyond the simple understanding of a previously encountered utterance (spoken or written). This would include, for example, learners' requests for new lexis they need in order to complete their utterances, or for further explanations about the grammar and syntax of previous phrases or expressions. The following is an example of this:

\section{TB 2.1}

In this sequence the teacher is checking homework

$01 \mathrm{~T} \quad{ }^{\circ}$ okay ${ }^{\circ}$, all the way round.

$02 \rightarrow \quad$ F1 $\quad$ sorry, (.) it's uncountable (.) way?

$03 \quad((2))$

04 T e:::r (.) $\uparrow$ no you can say one way two way- this is an expression 05 all the way

In line 01 the teacher completes an IRF sequence with her follow-up move. In line 02 the learner takes the initiative to ask a question. This is at an appropriate place for speaker change, but the fact that the learner prefaces her 
question with 'sorry' would seem to indicate that she is oriented to the institutional discourse which would anticipate a teacher's Initiation as the next turn. The learner's question is the first pair part of an adjacency pair and makes relevant an answer by the teacher. However, rather than respond, there is a two second pause and then a hesitation marker at the start of the teacher's turn. In CA terms, this is accountable behaviour. According to Pomerantz (1985, p. 152), in conversation, where a response is made relevant but is not forthcoming, "the speaker routinely sees the recipient's behaviour as manifesting some problem and deals with it". However, such repair is often absent from institutional discourse where such pauses are not uncommon as the recipient formulates an answer. This is not only the case in the classroom, but also, for example, in doctor-patient interaction. $^{1}$

Therefore, in the context of institutional discourse of the classroom, where the teacher is information provider, controls the floor and 'owns' the next turn, the learner does not attempt to deal with the trouble and waits for the teacher's answer. Moreover, in conversation, because a non-response to a First Pair Part is accountable, the addressee will normally fill the slot with a marker of recipiency (usually a minimal response), allowing time for a response to be formulated. In institutional contexts, on the other hand, this is not necessary and is omitted by the teacher. This sequence demonstrates how both the learner and the teacher are orienting to the institutional context.

Pauses following learner initiative are not unusual in the database and could be a marker of the unexpected nature of the turn, from the teacher's point of

\footnotetext{
${ }^{1}$ I would like to thank one of the anonymous reviewers for this observation
} 
view, which is not part of the institutionalised turn-taking system. Effectively, learners are speaking out of turn.

\subsection{Hypothesis testing}

The final function of initiative is what Allwright and Bailey (1991, p. 93) call 'hypothesis testing'. This term is used to refer to those cases when learners 'try out' their understanding of new language, which will then either be confirmed or corrected by the teacher. It generally concerns new lexis and may take the form of 'trying out' a paraphrase, spelling or translation. The following is an example:

\section{TE 1.8}

$01 \mathrm{~T} \quad \uparrow$ we say (.) another word per $<$ la te:rra $>$, (for earth) (.) no?

02 another word for for example when you pick up some earth 03 outside,

$04 \quad((1))$

$05 \mathrm{~T} \quad$ or in your garden:, you call that $\underline{\mathrm{s}: \text { :oil. }}$.

$06 \quad((2))$ ((sound of chalk on blackboard))

$07 \quad \mathrm{M} \quad$ soi[1]

$08 \quad \mathrm{M} \quad$ [s]oil?

09 T ahha::

$10 \quad \mathrm{M} \quad$ soil?=

$11 \mathrm{M}=$ [ah soil $]$

$12 \rightarrow \mathrm{F} \quad$ [terriccio]

$13 \mathrm{~T} \quad$ si (= yes) terriccio. soil.

This example is interesting for the use of code-switching. The teacher first uses the Italian word 'terra' in her explanation of the word earth in line 01 . In line 12 , the learner proffers a translation of the word 'soil' to test whether her understanding is correct or not. Her use of the L1 here is legitimised by the teacher's use of L1 in the initial explanation and in this way the learner aligns herself to the teacher. This alignment is acknowledged by the teacher in line 13 as she orients to the learner's use of the L1 and confirms the hypothesis. 


\section{Learner initiative and teacher responses}

Walsh (2006, p. 5) characterizes classroom discourse as follows

The features of second language classroom discourse $[\ldots . .$.$] present a very$ clear structure, where teachers control both the topic of conversation and turn-taking. Students take their cues from the teacher through whom they direct most of their responses.

In this characterisation of classroom discourse, learner initiative is not built into the institutional turn-taking system of the classroom and this is supported by the data in the study reported here, which show that there is no clear pattern in terms of where learner initiative occurs in interactional sequences,

Moreover, although interruptions were relatively rare in the data, hesitations and delays in teacher responses (see, for example, line 03 in TB 2.1) together with overlaps by both learners and teachers (see, for example, lines 06-09 in TB 2.3) seem to be relatively frequent occurrences in sequences involving learner initiative. Short overlaps are considered by Sacks et al. (1974) to be normal in ordinary conversation, especially when next speaker self-selects, but are less likely in institutional discourse, where turn-taking patterns should be more constrained. The existence of the features listed above indicates that learners do have opportunities to practise their interactional management skills (Allwright, 1984). In fact, the analysis of the extracts in the previous section has shown how learners are capable of successfully undertaking complex interactional work in teacher-fronted interaction (see TB 2.3, for example). 
By taking the initiative, learners effectively take control of the interaction and determine its trajectory. As Markee (2004, p. 585) points out, when learners take the initiative, they:

own the question and (potentially) the comment turns, while teachers are now sequentially obligated to do the answer turns.

From a pedagogic point of view, by taking the initiative, learners are undoubtedly "individualizing the instruction they are receiving, making it relevant to their own particular needs" (Allwright, 1984, p. 161). They are creating 'Practice opportunities' both for themselves and for other learners (ibid., p. 167). However, what happens to that learner initiative depends on the teacher's reaction to it. Therefore, it is the teacher's response which will ultimately determine whether the learner's contribution becomes an opportunity for learning or not (Kumaravadivelu, 1993).

\subsection{Teacher response to learner initiative}

Teacher response clearly depends to an extent on the nature of the initiative. If the initiative is a confirmation check oriented to activity, then a simple yes/no answer may be entirely appropriate. However, an examination of the data shows that where a range of options are open to teachers, there is great variety in teacher responses to learner initiative, ranging from trying to deal with it as quickly as possible in order to get back to the 'main business' of the lesson, to using it as a teaching and learning opportunity, to incorporating it into the lesson plan or even changing the direction of the lesson entirely.

The following sequence is an example of how learner initiative can affect 
the direction of a lesson and even lead to role reversal, creating opportunities for learning for the teacher. In this extract the group is doing a pre-listening activity in which the book presents a list of jobs. The learners have to choose from the list which ones they think the person in the listening text might have had. The teacher has just read out the list and her first move is an elicitation.

\section{$\underline{\text { TD } 1.12}$}

\begin{tabular}{|c|c|c|}
\hline 01 & $\mathrm{~T}$ & what jobs do you think he might have had? \\
\hline 02 & & $((1))$ \\
\hline 03 & $\mathrm{~T}$ & okay, che (.) che lavori pensate che:: \\
\hline 04 & & $(((1))$ \\
\hline 05 & $\mathrm{~T}$ & $\begin{array}{l}\text { può darsi (.) abbia [avuto (what what jobs do you think that } \\
\text { perhaps he had) }\end{array}$ \\
\hline 06 & M1 & [a spy \\
\hline 07 & $\mathrm{~T}$ & spy? what's a spy? it's it's (.) it's similar to Italian, \\
\hline 08 & F1 & un spia \\
\hline 09 & $\mathrm{~T}$ & right [okay. \\
\hline $10 \rightarrow$ & $\mathrm{F} 2$ & [and . stockbroker? \\
\hline 11 & & T what's a $\uparrow$ stockbroker? \\
\hline 12 & LL & ((general murmurs)) \\
\hline 13 & $\mathrm{~T}$ & someone who::, (.) works (.) on the stock excha::nge. \\
\hline $\begin{array}{l}14 \rightarrow \\
15 \\
16\end{array}$ & M2 & 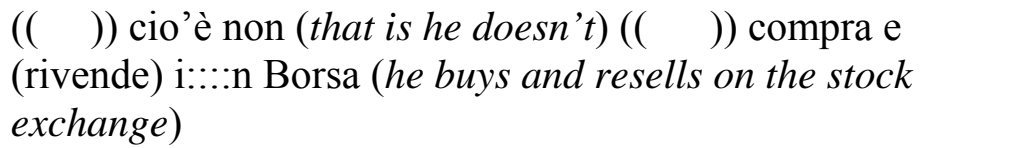 \\
\hline 17 & $\mathrm{~T}$ & yeah (.) okay una borsista, $=($ someone who has a grant $)$ \\
\hline $18 \rightarrow$ & M2? & $=$ borsista no \\
\hline 19 & $\mathrm{~T}$ & non si dice? (you don't say that) \\
\hline 20 & M2? & no \\
\hline 21 & $\mathrm{~T}$ & okay someone who $<$ BUYS and SELLS (.) $\underline{\text { shares }>}$ azioni \\
\hline 22 & & compra vende. (shares he buys he sells) \\
\hline 23 & & $((1))$ \\
\hline 24 & & okay? \\
\hline 25 & & $((2))$ \\
\hline $26 \rightarrow$ & F3 & e (= and) soldier::? \\
\hline $27 \rightarrow$ & F4 & soldier [si (yes) \\
\hline 28 & $\mathrm{~T}$ & [soldier? what's a soldier. \\
\hline 29 & LL & soldato \\
\hline 30 & $\mathrm{~T}$ & yeah, (.) okay. soldato, (.) easy, \\
\hline 31 & & $((1))$ \\
\hline 32 & $\mathrm{~T}$ & right (.) member of parliament? \\
\hline
\end{tabular}

In line $06, \mathrm{M} 1$ answers the teacher's elicitation with a suggestion from the list of 
jobs. In line 07, instead of giving Feedback on the learner's response, the teacher initiates another sequence to proffer a clarification request to check that the rest of the class knows what the word 'spy' means. In line $10 \mathrm{~F} 2$ takes the initiative with a clarification request of her own to ask what 'stockbroker' is (another job on the list) thereby aligning her talk in an interactionally sophisticated way to that of the teacher. The teacher responds with a counter-question, which, according to Markee (2004) serves as a means for the teacher to regain control of the interaction as such questions reposition learners as next speakers, shifting the interaction back to an IRF pattern. However, no clear response is forthcoming and the teacher responds herself in line 13. This is followed by M2's comprehension check. The teacher confirms the learner's comprehension in line 17, but in so doing uses the wrong Italian word, thus initiating a repair sequence, which is interactionally interesting in the context of the asymmetry of classroom discourse. In line 18, M2 points out the teacher's error in a very direct way, which would perhaps be unexpected by the less powerful partner in asymmetrical discourse. The teacher asks for confirmation of her error in line 19 before paraphrasing in English and Italian in lines 21-22. Lines 17-22 are particularly interesting for the role reversal that takes place as the teacher momentarily becomes learner, showing that learner initiative can potentially create learning opportunities for teachers as well.

In line 25, there is a two second pause. As pointed out in the analysis of extract TB 2.1, this is an accountable silence as, in conversational terms, 'okay' is the first part of a question-answer adjacency pair. However, the teacher does not treat the pause as accountable or pursue a response. Moreover, the learners orient to it 
as a sign that the side sequence is now complete (the teacher has reformulated her original explanation) and therefore provide the next response in the original series. Teacher and learners are thereby again demonstrating interactional sensitivity to the institutional context. The pause in line 25 is followed by further initiatives as F3 and F4 jointly make their own clarification request. This is again followed by teacher counter-question, learner response and teacher follow-up. In line 32, the teacher starts a new IRF sequence, but this time she aligns with the learners and shifts her elicitation to asking about the remaining vocabulary. Through repeated initiative and alignments, this sequence shows a shift from eliciting answers to a pre-listening task to vocabulary presentation/revision in a way that was clearly more closely suited to the learners' needs.

The reasons underlying the different teacher responses to learner initiative, and indeed underlying any in-class decision by the teacher, are obviously complex and go beyond the scope of this study (but see Bailey, 1996 who lists six possible reasons for teachers' in-class decisions to change their lesson plans). However, accepting and encouraging learner initiative would seem to fulfil some of the conditions identified in SLA research for successful language acquisition.

\section{Implications}

The data presented here have shown that the pedagogical context (Seedhouse, 2004) seems to determine the type and the amount of initiative to a great extent. Learners were found to take the initiative more in Form and Accuracy contexts and in Procedural contexts, with 135 of the 206 instances of initiative taking place in these two contexts. 
Learner initiative also involves learners in practising complex interaction management skills in the co-construction of the institutional discourse of the classroom. Initiative frequently leads to the use of utterances, such as confirmation checks and clarification requests, that are considered by SLA researchers as important in language learning (Long, 1983; Pica 1987).This point is potentially significant, given that Pica (1987) maintained that such features are generally not found in classroom discourse outside task-based interaction, which was not the approach used in any of the lessons in the database analysed for this study. The analysis presented here has therefore shown how attention to the nature of the interaction reveals a much more subtle and potentially accurate picture of classroom discourse than can be obtained via the application of categories determined a priori.

Given that learner initiative potentially involves both language input (Krashen, 1985) and output (Swain, 1985), initiative can nearly always be seen as representing a learning opportunity and should be encouraged by adjusting interaction patterns to better accommodate learner initiative and utilising learning opportunities created by learners.

As Walsh (2006) notes, learning opportunities can be increased if teachers are made aware of the relationship between classroom interaction and language learning. Teacher education programmes can help teachers to understand interactional processes through, for example, the study of classroom recordings and lesson transcripts (Borg, 1998; Thornbury, 1996; Walsh, 2002, 2006). In this way, teachers can be shown how to encourage learner initiative by giving learners more space and more time, two key conditions for promoting initiative (Author). 
Giving learners more space means using learning opportunities created by the learners themselves, for example, allowing learners to develop topics or activities and take a more active role in managing their own learning. Giving learners more time means increasing the 'wait time' (Thornbury, 1996) before teachers take the turn again in the absence of learner response. The data presented here show numerous instances where two or three second pauses following a teacher question in fact led to learners self-selecting as next speaker in order to request information or clarification.

However, learners' strong orientation to the institutional discourse of the classroom means they may not automatically embrace any new time or space they are given. If the learners' perceptions do not coincide with those of the teacher, there may be a mismatch of expectations. Musumeci (1996) found that while one teacher in her study seemed to encourage learners to take the initiative in order to reach understanding, with a potentially positive effect on their linguistic development, from the learners' point of view this may have meant that her explanations were simply not clear. There is the danger then that encouragement of learner initiative may be interpreted by the learners as signs of a poorly prepared teacher and a badly run lesson. It is important for the teacher to ensure that there is no mismatch of expectations and that learners clearly understand their role.

\section{Conclusion}

The role of classroom interaction, and especially teacher-fronted interaction in promoting language learning is now widely accepted in classroom research. 
Moreover, it is now recognised that learner initiative, participation and involvement in instruction represent an important aspect of classroom interaction. What this study has done is to present a microanalysis of learner initiative, participation and involvement in order to better understand the co-construction of intersubjective understanding in the classroom. It has identified some of the ways in which learners actively contribute to what has been previously seen as a more rigid form of interaction. Far from being constrained by the classroom turn-taking system, learners are able to engage in complex and sophisticated interactional work. They can take control of the organisational sequences in classroom talk, depending on the type of activity they are involved in, so as to direct the interaction in a way that better suits their learning needs. The implications for teachers are clear: opportunities for learner participation in the learning process need to be created by allowing "for greater variability in the patterns of communication" (Johnson 1995, p.45) in the classroom and accepting learners as co-participants in building the interaction that takes place there.

6547 words

\section{Acknowledgements}

I would like to thank the two anonymous reviewers for their very constructive and helpful comments. I would also like to thank Keith Richards for his invaluable and insightful suggestions on the various drafts of this paper, as well as Anne Burns and Julian Edge for their comments on an earlier draft. Any weaknesses remain my own.

\section{Appendix}




\section{Transcription conventions}

Sequences are labelled according to the teacher involved, the lesson the sequence is from and the order in which it appears. Therefore TA 2.3 is the third sequence from the second lesson of Teacher A.

Transcription conventions are based mainly on those of used by in Richards and Seedhouse (2005). Identified learners have been given pseudonyms

$\mathrm{T} \quad$ indicates the teacher

F indicates an unidentified female learner

M indicates an unidentified male learner

(where an unidentified learner takes more than one turn in a sequence or more than one unidentified learner of the same sex speaks in a sequence, then numbering is used)

$\rightarrow \quad$ indicates a relevant turn

[ indicates onset of overlapping utterances

] indicates the end of overlapping utterances

$=\quad$ indicates run on turns, either by the same or different speakers

(10) the approximate length of pauses longer than one second

(.) indicates a short untimed pause

word indicates speaker emphasis

ye::s indicates a drawn out syllable

indicates an abrupt cut-off

? $\quad$ rising intonation, but not necessarily a question 
! emphatic tone

low-rise intonation, suggesting a continuation

LOUD capitals indicate a loud sound relative to surrounding talk

$\circ \quad$ indicates notably quieter talk

$\uparrow \quad \downarrow \quad$ indicate higher or lower pitch in the utterance following the arrow

$><\quad$ indicate that talk they surround is notably quicker that surrounding

talk

$<>\quad$ indicates the talk they surround is slow and deliberate

( ) indicates unintelligible speech

(guess) indicates uncertain transcription

(yes) indicates translation of Italian text. An approximate English translation is given, not a literal one.

((laughs)) is used for non-verbal actions

[i:] is used for phonetic transcription of sounds or of non-standard

pronunciation

Pauses above one second are considered as gaps and indicated on a separate line.

Shorter pauses are considered hesitations and included within a turn or at the

beginning (indicating a hesitation by next speaker before starting a turn).

\section{References}

Allwright, D. (1984). The importance of interaction in classroom language learning. Applied Linguistics, 5(2), 156-171.

Allwright, D., \& Bailey, K. M. (1991). Focus on the Language Classroom. Cambridge: Cambridge University Press.

Bailey, K. M. (1996). The best laid plans: teachers' in-class decisions to depart from their lesson plans. In K. M. Bailey \& D. Nunan (Eds.), Voices from the Language Classroom. Cambridge: Cambridge University Press.

Borg, S. (1998). Data-based teacher development. ELT Journal, 52(4), 273-281. 
Coulmas, F. (Ed.). (1981). Conversational Routine. The Hague: Mouton.

Cullen, R. (1998). Teacher talk and the classroom context. ELT Journal, 52(3), $179-187$.

Cullen, R. (2002). Supportive teacher talk: the importance of the F-move. ELT Journal, 56(2), 117-127.

Drew, P., \& Heritage, J. (1992). Analyzing talk at work: an introduction. In P.Drew \& J. Heritage (Eds.), Talk at Work. Cambridge: Cambridge University Press.

Greenleaf, C., \& Freedman, S. W. (1993). Linking classroom discourse and classroom content: following the trail of intellectual work in a writing lesson. Discourse Processes, 16, 465-505.

He, A. W. (2004). CA for SLA: arguments from the Chinese language classroom. The Modern Language Journal, 88(iv), 568-582.

Jarvis, J., \& Robinson, M. (1997). Analyzing educational discourse: an exploratory study of teacher response and support to pupils' learning. Applied Linguistics, 18(2), 212-228.

Johnson, K. E. (1995). Understanding Communication in Second Language Classrooms. Cambridge: Cambridge University Press.

Kasper, G. (2001). Four perspectives on L2 pragmatic development. Applied Linguistics, 22, 502-530.

Krashen, S. (1985). The Input Hypothesis. London: Longman.

Kumaravadivelu, B. (1993). Maximizing learning potential in the communicative classroom. ELT Journal, 47(1), 12- 21.

Kumaravadivelu, B. (2001). Toward a postmethod pedagogy. TESOL Quarterly. 35(4), 537-560.

Levinson, S. (1983). Pragmatics. Cambridge: Cambridge University Press.

Liddicoat, A. J. (2007). An Introduction to Conversation Analysis. London: Continuum.

Long, M. H. (1983). Linguistic and conversational adjustments to nonnative speakers. Studies in Second Language Acquisition, 5, 177-193.

Markee, N. (2004). Zone of interactional transition in ESL classes. The Modern Language Journal, 88(iv), 583-596.

Markee, N. (2008). Toward a learning behaviour tracking methodology for CAfor-SLA. Applied Linguistics, 29(3), 404-427.

Markee, N., \& Kasper, G. (2004). Classroom talks: an introduction. The Modern Language Journal, 88(iv), 491-500.

Mehan, H., \& Griffin, P. (1980). Socialization: the view from classroom interactions. Sociological Enquiry, 50(3-4), 357-392.

Musumeci, D. (1996). Teacher-learner negotiation in content-based instruction: communication at cross-purposes? Applied Linguistics, 17(3), 286-324.

Nassaji, H., \& Wells, G. (2000). What's the use of 'Triadic Dialogue': An investigation of teacher-student interaction. Applied Linguistics, 21(3), 376-406.

Pica, T. (1987). Second-language acquisition, social interaction and the classroom Applied Linguistics (Vol. 8, pp. 3-21).

Pica, T., Young, R., \& Doughty, C. (1987). The impact of interaction on comprehension. TESOL Quarterly, 21(4), 737-758.

Pomerantz, A. (1985). Pursuing a response. In J. M. Atkinson \& J. Heritage 
(Eds.), Structures of Social Action (pp. 152-).

Sacks, H., Schegloff, E. A., \& Jefferson, G. (1974). A simplest systematics for the organization of turn-taking for conversation. Language, 50(4), 96-735.

Seedhouse, P. (1996). Classroom interaction: possibilities and impossibilities. ELT Journal, 50(1), 16-23.

Seedhouse, P. (2004). The Interactional Architecture of the Language Classroom: A Conversation Analysis Perspective. Malden:MA: Blackwell Publishing.

Swain, M. (1985). Communicative competence: some roles of comprehensible input and comprehensible output in its development. In S. Gass \& C. Madden (Eds.), Input in Second Language Acquisition. Rowley: Newbury House.

Thornbury, S. (1996). Teachers research teacher talk. ELT Journal, 50(4), 279288.

van Lier, L. (1988). The Classroom and the Language Learner. London: Longman.

Walsh, S. (2002). Construction or obstruction: teacher talk and learner involvement in the EFL classroom. Language Teaching Research, 6(1), 323.

Walsh, S. (2006). Investigating Classroom Discourse. Abingdon: Routledge. 